\title{
FORMAÇÃO DE PROFESSORES DE PORTUGUÊS COMO LÍNGUA ESTRANGEIRA (PLE) EM UM CENTRO DE LÍNGUAS EM CONTEXTO UNIVERSITÁRIO
}

\author{
FORMACIÓN DEL PROFESORADO DE PORTUGUÉS COMO LENGUA \\ EXTRANJERA (PLE) EN UN CENTRO DE IDIOMAS EN UN CONTEXTO \\ UNIVERSITARIO
}

\section{PORTUGUESE AS A FOREIGN LANGUAGE (PFL) TEACHER EDUCATION IN A LANGUAGE CENTRE IN A UNIVERSITY CONTEXT}

\author{
Douglas Altamiro CONSOLO ${ }^{1}$
}

RESUMO: Apresento, neste relato de experiências, a formação de professores de português como língua estrangeira (PLE), enquanto formação pré-serviço, em um Centro de Línguas e Desenvolvimento de Professores (CLDP) do IBILCE-UNESP. A formação específica de professores de PLE no curso de Licenciatura em Letras naquela universidade restringe-se, até o momento, a uma disciplina obrigatória sobre PLE e ao engajamento dos alunos em projetos de extensão. Por outro lado, licenciandos em Letras que atuam como tutores no CLDP da mesma universidade têm a oportunidade de refletir sobre o ensino e a aprendizagem de PLE, de elaborar cursos e materiais didáticos, e de ministrar cursos de PLE em co-docência com seu professor-orientador. Essa formação complementar de professores de PLE no âmbito do CLDP tem se mostrado bastante satisfatória, além do fato de podermos, dessa maneira, oferecer cursos de PLE para alunos estrangeiros da comunidade acadêmica e da comunidade externa à universidade.

PALAVRAS-CHAVE: Centro de línguas. Formação de professores. Licenciatura em Letras. Português como língua estrangeira.

RESUMEN: En este relato de experiencia, presento la formación de profesores de portugués como lengua extranjera (PLE) en un Centro de Idiomas y Desarrollo Docente (CLDP) de IBILCE-UNESP. La formación especifica de los profesores de PLE en la carrera de Licenciatura en Letras de esa universidad, hasta el momento, se restringe a una disciplina obligatoria, en PLE, y a la participación de los estudiantes en proyectos de extensión. Los graduados en Letras que actúan como tutores en el CLDP de la misma universidad tienen la oportunidad de reflexionar sobre la enseñanza y el aprendizaje de PLE, de elaborar cursos y materiales didácticos, y de impartir cursos de PLE con sus maestro-consejero. Esta formación complementaria de profesores PLE dentro del CLDP ha demostrado ser muy satisfactoria, además de que podemos, de esta forma, ofrecer cursos PLE a estudiantes extranjeros de la comunidad académica y de la comunidad externa a la universidad.

1 Universidade Estadual Paulista (UNESP), São José do Rio Preto - SP - Brasil. Departamento de Letras Modernas. ORCID: https://orcid.org/0000-0001-6247-8657.E-mail: douglas.consolo@unesp.br 
PALABRAS CLAVE: Centro de idiomas. Formación de professores. Grado en Letras. Portugués como lengua extranjera.

ABSTRACT: In this paper, I report on experiences of Portuguese as a foreign language (PFL) teacher education, as pre-service teacher development, in a language center and teacher development extension project at IBILCE-UNESP. Portuguese teacher development in the Letters degree at that university has currently been restricted to only one compulsory course subject about PFL in the curriculum, and to students' participation in extension projects. On the other hand, Letters undergraduates who act as teachers in the CLDP-IBILCE have the opportunity to reflect about the teaching and learning of PFL, to plan courses and course materials, and to teach PFL lessons in co-teaching partnerships with their supervisor. The complementary experience of teacher development in the CLDP has proved to be very satisfactory, besides the fact that PFL courses can be offered to students from both the university and the outside communities.

KEYWORDS: Language center. Teacher education. BA in Letters. Portuguese as a foreign language.

\section{Introdução}

A formação de professores de português como língua estrangeira (PLE) constitui-se em área de conhecimento e em ação pedagógica importantes no que tange a preparação de docentes aptos a atuarem em contextos de ensino de português enquanto língua não materna, no Brasil e em outros países. E, apesar de se caracterizar como uma área de pesquisa relativamente nova no Brasil, "visto que é ao final dos anos 1980 que surgem os primeiros sinais de emergência de instituição e institucionalização do PLE como campo de conhecimento" (ALMEIDA FILHO, 2012; ROCHA, 2021, p. 746) no contexto brasileiro, diversas ações de ensino e de pesquisa em PLE já se concretizaram nas últimas três décadas.

Sabe-se, historicamente, que muitos professores de PLE adentraram à docência nessa área oriundos de outras áreas de ensino de línguas, dentre as quais o português como língua materna e outras línguas estrangeiras nas quais se formaram professores. Esses profissionais vêm atuando satisfatoriamente no ensino de PLE, tanto no contexto brasileiro, como no exterior. Entretanto, dados o crescimento da demanda pelo ensino de $\mathrm{PLE}^{2}$ nos últimos anos e as especificidades do ensino da língua portuguesa a falantes de outras línguas, torna-se cada vez mais necessário investir em uma formação específica desses professores, analogamente, por

${ }^{2}$ Utilizo, neste artigo, o termo PLE (português como língua estrangeira) para me referir a todas as possibilidades de ensino e aprendiza gem da língua portuguesa a falantes de outras línguas, contemplando, por exemplo, português como língua de acolhimento (PLAc), como língua a dicional(PLA) e como língua de herança (PLH). 
exemplo, ao que já acontece na formação de docentes de línguas estrangeiras em cursos de licenciatura em Letras no Brasil.

Apresento, neste artigo, experiências sobre a formação de professores de PLE, como formação pré-serviço, em um Centro de Línguas e Desenvolvimento de Professores (CLDP) de um dos campus da UNESP (Universidade Estadual Paulista "Júlio de Mesquita Filho"), uma universidade pública no estad o de São Paulo, Brasil. Trata-se do campus da cidade de São José do Rio Preto, onde situa-se o Instituto de Biociências, Letras e Ciências Exatas (IBILCE), um dos três campus da referida universidade nos quais oferecem-se cursos de formação inicial (préserviço) de professores de línguas, a saber, de Licenciatura em Letras. Nesses cursos, todos de licenciatura dupla, os alunos se formam professores de línguas portuguesa, para lecionar português principalmente nos contextos da escola regular no Brasil, e também professores de uma língua estrangeira. No caso específico do curso de Licenciatura em Letras do IBILCE, as línguas oferecidas regularmente são o espanhol, o francês, o inglês e o italiano. Em anos anteriores, entre 2016 e 2018, foram também oferecidos cursos de alemão, de russo e de grego moderno, ministrados por docentes voluntários

A formação de professores de PLE no currículo do curso de Licenciatura em Letras na universidade restringe-se, até o momento, a uma disciplina obrigatória de 60 horas, atualmente ministrada por uma docente do Departamento de Educação do IBILCE, e ao engajamento dos alunos, quando possível, em projetos de extensão.

Os CLDPs, um projeto de extensão implementado e apoiado pela Pró-Reitoria de Extensão da UNESP (PROEX), concretizou-se nos campi das cidades de Araraquara, Assis e São José do Rio Preto desde $2013 .^{3}$

As aulas de línguas oferecidas pelos CLDPs são ministradas por docentes denominad os “tutores”, que são licenciandos em Letras interessados em uma formação complementar e na experiência de ensinar uma língua estrangeira na qual são bastante proficientes, geralmente a língua estrangeira que estudam em seu curso de graduação. A escolha dos tutores é realizada anualmente, por meio de inscrição e de um processo seletivo. Cada tutor é orientado por um docente do Departamento de Letras Modernas de seu campus, especialista na respectiva língua estrangeira. No caso da orientação dos tutores de PLE, embora eu seja docente da área de Língua Inglesa, assumi essa função desde a implementação do CLDP no IBILCE, uma vez que (ainda) não há docentes contratados na UNESP para a área de PLE. Os tutores recebem uma bolsa concedida pela PROEX ou advinda da verba de inscrições dos alunos, tanto da própria

${ }^{3}$ Maiores informações sobre o CLDP do IBILCE-UNESP Disponíveis em: https://www.ibilce.unesp.br/\#!/centrode-linguas-1/ 
UNESP (comunidade interna) como da comunidade externa, nos cursos do CLDP. E, mais recentemente, tal experiência docente inclui a docência em cursos de PLE na modalidade online. ${ }^{4}$

Na sequência deste artigo apresentam-se, na próxima seção, informações sobre o cenário atual da formação de professores de PLE no Brasil; na seção subsequente, um relato da formação complementar de professores de PLE no CLDP-IBILCE; em seguida, as considerações finais e as referências bibliográficas aqui utilizadas.

\section{A formação de professores de PLE no Brasil}

A formação específica de professores de PLE no Brasil ocorre das seguintes maneiras: cursos de graduação; disciplinas curriculares, algumas de caráter optativo; disciplinas de pósgraduação; cursos de especialização (pós-graduação lato sensu); e projetos de extensão. Trato, a seguir, dessas possibilidades de formação docente em PLE, com base em informações trazidas por Scaramucci e Bizon (2020, ALMEIDA; ROCHA, 2021) e por Furtoso (2015), e também obtidas por meio de contatos com colegas que atuam na área de PLE.

Cursos de graduação em PLE são oferecidos nas seguintes universidades: Universidade de Brasília (UnB-DF), Universidade Federal da Bahia (UFBA-BA), Universidade Federal da Integração Latino-Americana (UNILA-PR) e Universidade Estadual de Campinas (UNICAMP-SP). Maiores informações sobre essas licenciaturas encontram-se disponíveis na internet, nas páginas das respectivas universidades, em Almeida e Rocha (2021), e em Scaramucci e Bizon (2020). Sobre o curso de Licenciatura em Língua Portuguesa, do Instituto Federal de Goiás (IFG), menciona-se, em um link de divulgação do curso na internet (http://cursos.ifg.edu.br/info/lic/lic-letras/CP-GOIANIA), que "O curso de Letras do IFG possui como diferencial a formação de professores de Português como língua estrangeira”, embora, segundo informação recebida de um docente do IFG, o referido curso não oferece licenciatura em PLE.

Disciplinas curriculares sobre PLE, algumas de caráter optativo, são oferecidas pelas seguintes universidades: UnB-DF, UNICAMP-SP, Universidade Federal de Juiz de Fora (UFJF-MG), Universidade Federal da Integração Latino-Americana (UNILA-PR), Universidade Estadual de Londrina (UEL-PR), Universidade Federal do Rio Grande do Sul (UFRGS-RS), Universidade Estadual do Rio de Janeiro (UERJ-RJ) e Universidade Estadual

4 Para maiores informações e reflexões sobre ensino emergencial durante a pandemia do covid -19, Disponível em: Cordeiro (2020) e Hodges et al. (2020). 
Paulista "Júlio de Mesquita Filho" (UNESP-SP). No caso específico do IBILCE-UNESP, conforme mencionado anteriormente, trata-se da disciplina "Português língua estrangeira: ensino e formação docente", de 60 horas, obrigatória aos alunos dos cursos de Licenciatura em Letras daquele campus.

Disciplinas sobre PLE e projetos em nível de pós-graduação strictu sensu (Mestrado e Doutorado) estão presentes, por exemplo, na UNICAMP, na UNESP, na Universidade Federal Fluminense (UFF-RJ) e na Universidade Federal do Paraná (UFPR-PR).

Em termos de cursos de especialização, cursos de pós-graduação lato sensu são oferecidos, por exemplo, no IBILCE-UNESP, na Universidade Estadual de Londrina (UEL e na Universidade Federal Fluminense (UFF).

Sobre projetos de extensão, considerada a "parte mais robusta do tripe" (ensino/extensão/pesquisa) em PLE no Brasil, segundo afirmação de Furtoso (2015), há projetos, por exemplo, na Universidade Federal do Amazonas (UFAM-AM), na UNESP, na Universidade Federal de Minas Gerais (UFMG-MG), na Universidade Federal de São Carlos (UFSCAr-SP), na Pontifícia Universidade Católica do Rio de Janeiro (PUC-RJ), na UFPR, na UFRGS e na Universidade Federal do Rio de Janeiro (UFRJ-RJ). ${ }^{5}$

Embora alguns cursos de licenciaturas em PLE tenham sido criados no Brasil, nos últimos anos, além da existência das outras modalidades de formação acima citadas, a formação docente em PLE no contexto brasileiro ainda é limitada, considerando-se, por exemplo, as demandas de ensino e aprendizagem de PLE no Brasil e em outros países, e o fato de o Brasil ser o maior país onde se fala português como língua materna.

\section{A formação de professores de PLE no CLDP-IBILCE}

Os CLDPS da UNESP têm dois objetivos principais: o oferecimento de cursos optativos de línguas estrangeiras a membros das comunidades interna e externa à universidade, e a formação complementar de professores de línguas estrangeiras.

Conforme acima mencionado, os tutores das línguas oferecidas pelos CLDPs são discentes em formação para a docência, ou seja, cursam disciplinas de línguas e de literaturas estrangeiras, de didática, de Linguística Aplicada e de prática de ensino, importantes para a sua formação docente inicial; além das disciplinas obrigatórias de estágios de docência, nos últimos anos dos cursos de Licenciatura em Letras. Todavia, de acordo com relatos de alunos dos

${ }^{5}$ Maiores informações sobre a forma ção de professores de PLE no Brasil Disponível em: Almeida e Rocha (2021), e Scaramuccie Bizon (2020). 
últimos anos do referido curso, sua formação nem sempre contempla, de maneira abrangente e suficientemente aprofundada, questões de ensino e aprendizagem de línguas importantes para a sua formação enquanto futuros professores de línguas. Parte das disciplinas do curso dedicase à formação para a pesquisa, nas áreas de Estudos Linguísticos e de Literatura. Por essa razão, a oportunidade de atuar como tutores nos CLDPs lhes proporciona oportunidade de formação complementar, contemplando, inclusive, questões tanto teóricas como práticas da docência em línguas não tratadas nas disciplinas de suas licenciaturas.

Nos últimos três anos, tem-se verificado um aumento significativo no interesse e no número de tutores atuantes no CLDP-IBILCE, principalmente devido ao aumento da demanda pelos cursos de línguas e à possibilidade de recebimento de bolsas, viabilizada graças ao apoio de UNESP e à verba recolhida das inscrições nesses cursos.

Os cursos de PLE oferecidos atualmente pelo CLDP-IBILCE são os seguintes:

Nível básico (A1.1, A1.2, A2.1, A2.2) 6

Nível intermediário (B1)

Cursos com denominação específica: "Aspectos da Cultura Brasileira” (nível intermediário); “Interações Oral: Interações Acadêmicas" (nível básico); e "Interações Orais em Português Brasileiro" (nível intermediário).

Nos anos iniciais de funcionamento dos CLDPs, entre 2016 e 2017, foram planejados e implementados cursos online de PLE na Plataforma Moodle, nos níveis A1, A2 e B1, para atender estrangeiros em processo de vinda ao Brasil, para estudar ou realizar projetos de pesquisa em campi da UNESP. Na mesma época, desenvolveu-se um teste online de nivelamento para PLE, também na Plataforma Moodle.

A formação de professores de PLE no CLDP-IBILCE, concretizada nas ações do docente-orientador, por meio de reuniões pedagógicas regulares e acompanhamento do trabalho docente dos tutores, se caracteriza por seis aspectos principais, a saber: sugestões e orientações para planejamento de cursos e preparação de aulas pelos tutores; planejamento dos cursos, seleção de conteúdos e elaboração de materiais didáticos pelos tutores; docência nos cursos de PLE; reflexão dos tutores, com o orientador, sobre as aulas ministradas; submissão e apresentação de comunicações e painéis em eventos acadêmicos; e submissão de artigos para publicação, geralmente em co-autoria com o orientador.

Após a seleção dos alunos que atuarão como tutores de PLE, discutem-se, nas primeiras reuniões de orientação, as características gerais dos cursos a serem oferecidos, tais como dia(s)

${ }^{6}$ Níveis baseados no Quadro Europeu Comum de Referência (QECR) para proficiência em línguas. 
da semana e horário, carga horária, perfil (previsto) dos alunos, nível do curso (conforme os níveis do QECR), e metodologia de ensino. Os tutores são orientados a buscar conteúdos em materiais didáticos disponíveis em um conjunto de livros didáticos de PLE de propriedade do CLDP, em outros livros didáticos que porventura encontrem, em materiais utilizados anteriormente nos cursos do CLDP e na internet. Cada aula é elaborada nos moldes de uma estrutura de plano de aula, no qual se contemplam informações sobre o(s) objetivo(s) da aula, a metodologia de ensino, os materiais e as atividades didáticas, o(s) papel(éis) do professor e dos alunos na aula e os resultados de aprendizagem esperados.

Após a preparação dos planos das primeiras aulas de cada curso e dos materiais a serem utilizados - por exemplo, organizados em uma apresentação em formato de Power Point e handouts em formato de Word, os planos e os materiais didáticos são avaliados pelo orientador e discutidos com os tutores, sendo feitas adaptações e/ou modificações necessárias. O orientador participa integralmente das primeiras aulas e, na medida do possível, das demais aulas de cada curso.

Conforme apontado por Saujat (2004, p. 13-14, grifos do autor),

A concepção do prático reflexivo (SCHÖN, 1983) baseia-se em uma abordagem empírica que caracteriza o pensamento profissional como uma reflexão no curso da ação, reflexão que incide sobre essa ação e sobre a conduta num determinado contexto. Esse saber não se formula, mas encontrase incorporado e é a fonte da eficiência da atividade profissional, que pode ser representada como um diálogo dos profissionais com os problemas das situações com que se defrontam.

Semanalmente, orientador e tutores se reúnem para discutir o resultado das aulas ministradas na semana, o que caracteriza uma "reflexão no curso da ação". Nessas discussões, os tutores são conduzidos a refletir sobre as aulas ministradas: se as atividades foram bem sucedidas, se houve participação dos alunos, se o(s) objetivo(s) da aula foi(ram) atingidos, e se houve dificuldades, por parte dos tutores, em tratar de determinadas situações ocorridas nas aulas. Depois de ouvir os tutores, o orientador faz comentários sobre esses aspectos, sobre a fala do professor, tenha essa fala ocorrido em português ou em uma das línguas dos alunos, ${ }^{7} \mathrm{e}$ oferece sugestões de aprimoramento das ações docentes dos tutores. Dessa maneira, realiza-se a reflexão no curso da ação, conforme postulado por Schön (1983), no contexto da proposta dos cursos do CLDP e das ações docentes dos tutores, em um diálogo entre fatos, teorias, experiências do orientador e experiências dos discentes-tutores. A experiência da reflexão sobre

${ }^{7}$ Os tutores de PLE geralmente falam, a lém do português, espanhol, francês ou inglês. 
a ação a posteriori, ou seja, após a realização das aulas, confere novos conhecimentos para os professores em formação.

Saujat (2004, p. 14-15), citando Altet, apresenta, no âmbito da chamada abordagem ecológica dos processos interativos, na qual, em uma descrição ecológica da aula, "a complexidade da tarefa do professor se relaciona com os acontecimentos que aí ocorrem", o paradigma processos interativos contextualizados, definindo o ensino como "um processo interativo, interpessoal, intencional, finalizado pela aprendizagem dos alunos" (ALTET 1991 p. 16). Segundo Altet (1994 apud SAUJAT, 2004, p. 16),

Esse processo requer uma cultura profissional que se baseia em seis critérios (ALTET, 1994): (a) uma base de conhecimentos ligados ao agir profissional; (b) uma prática adaptada em situação complexa; (c) uma capacidade de dar conta de suas próprias competências e atos; (d) uma autonomia e uma responsabilidade pessoal no exercício de suas competências; (e) uma adesão a normas coletivas constitutivas da identidade profissional; (f) um pertencimento a um grupo que desenvolve estratégias de promoção e valorização.

Os tutores de PLE que atuam no CLDP-IBILCE agregam conhecimentos adquiridos em disciplinas da licenciatura, por meio de leituras indicadas pelo orientador e em outras experiências discentes, à sua prática docente nas situações específicas dos cursos que ministram, refletindo sobre e avaliando seu desempenho docente e o aprendizado dos alunos, inseridos em um cenário mais amplo de ensino e aprendizagem de línguas, a saber, o CLDP, a UNESP e o contexto brasileiro.

Ações específicas para enriquecer a formação docente dos tutores dos CLDPs ocorrem à medida que se verifica a necessidade de fortalecer essa formação, como aconteceu no início da pandemia de COVID-19, quando foi tomada a decisão de que todos os cursos de línguas dos CLDPs seriam oferecidos somente na modalidade online. Então, para preparar os tutores para o ensino remoto, antes do início dessas aulas online, ofereceu-se aos tutores um curso de 30 horas, também na modalidade online, sobre princípios, metodologia e recursos eletrônicos disponíveis para o ensino de línguas. O curso foi ministrado por três doutorandos, dos campi da UNESP de Araraquara e de Assis, supervisionados por suas respectivas orientadoras. No âmbito dessa ação formativa, ofereceu-se também a palestra de Consolo (2020), sobre avaliação no ensino e na aprendizagem de línguas.

Conforme apontado anteriormente, os tutores de PLE são incentivados a apresentar trabalhos em eventos acadêmicos e a produzir artigos para publicação, geralmente em coautoria entre tutores e/ou com o professor-orientador. 
Dentre as apresentações de trabalhos, cito as seguintes:

$\checkmark$ CONSOLO, D. A.; SONSINO SOARES, G. Interações orais em uma experiência de ensino de português como língua adicional em contexto multilíngue. Poster. III SINEPLA, 2021.

$\checkmark$ CONSOLO, D. A. An online placement test of Portuguese as a foreign language: Development and implementation. Poster. LTRC, 2021.

$\checkmark$ CONSOLO, D. A. Experiences of assessing and testing Portuguese as a foreign language (PFL): students online and in the classroom. Comunicação. IX EMEP, 2020.

$\checkmark$ CONSOLO,D. A. Avaliação e Testagem em PLE nas Modalidades Online e Presencial. Comunicação. II CIPLiNM, 2020.

$\checkmark$ CONSOLO, D. A. Formação de Professores de PLE em um Centro de Línguas em Contexto Universitário. Roda de Conversa. II CIPLiNM, 2020.

$\checkmark$ CONSOlO, D. A.; SANTOS, V. M. Aspectos Culturais, Ensino e Formação de Professores de PLE. Comunicação. I CIPLiNM, 2019.

$\checkmark$ CONSOLO, D. A.; SANTOS, V. M. Aspectos culturais do Brasil: uma experiência didática na formação de professores de PLE. Comunicação. SIMELP, 2019.

$\checkmark$ CONSOLO, D. A. Elaboração e Formação Inicial de Professores em um Curso de PLE Online. Comunicação: SELE - IBILCE/UNESP, 2017.

$\checkmark$ Sobre publicações, destaco os seguintes trabalhos:

$\checkmark$ CONSOLO, D. A.; SONSINO SOARES, G. Interações orais em uma experiência de ensino de português como língua adicional em contexto multilíngue. Artigo submetido à revista BELT, volume especial, anais do III SINEPLA 2021 (no prelo).

$\checkmark$ CONSOLO, D. A.; SONSINO SOARES, G.; TOJEIRA-RAMOS, J. P. 2021. PORTUGUES COMO LÍNGUA ESTRANGEIRA (PLE): ensino on-line e formação docente em um contexto de pandemia. Open Minds International Journal, v. 2, n. 1, 2021, p. 22-35.

$\checkmark$ CONSOLO, D. A.; SANTOS, V. M. A(s) cultura(s) brasileira(s) em sala de aula: o ensino de português como língua estrangeira em uma classe multilíngue. Portuguese Language Journal, v. 13, 2019, p. 82-104.

$\checkmark$ CONSOLO, D. A. Elaboração e Formação Inicial de Professores em um Curso de PLE Online. In: Simpósio SIPLE 2017, 2018, Lisboa-Portugal. ANAIS SIMPÓSIO SIPLE 2017. Londrina-PR: Universidade de Londrina (UEL), v. 1, 2018, p. 146-156.

$\checkmark$ CONSOLO, D. A.; SILVA, V. P. Desenvolvimento e Implementação de um Teste Online de Proficiência de Português como Língua Estrangeira. MOSAICO. UNESP: São José do Rio Preto, v. 15, 2016, p. 691-716.

A formação complementar de professores de PLE no âmbito do CLDP-IBILCE inclui, portanto, discussões e reflexões para a preparação dos cursos; docência e reflexão a posteriori; busca de alternativas e soluções para eventuais dificuldades e limitações encontradas pelos tutores no exercício da docência; apresentações de trabalhos em eventos acadêmicos e publicações. 


\section{Considerações finais}

A formação de professores de PLE no âmbito do CLDP-IBILCE, nos moldes acima relatados, tem se mostrado bastante satisfatória. Os tutores vivenciam experiências significativas de ensino de português a falantes de outras línguas, desde a preparação de suas aulas e da elaboração e/ou seleção dos materiais didáticos, e da preparação e utilização de instrumentos e/ou procedimentos de avaliação, até as reflexões sobre essas experiências, com os professores-orientadores, e decorrentes encaminhamentos para suas futuras aulas de PLE.

Além dessa formação complementar - e específica sobre PLE; destaco o fato de podermos, dessa maneira, oferecer cursos de PLE para alunos estrangeiros da comunidade acadêmica e da comunidade externa à universidade. E, com a realidade dos cursos ofertados na modalidade online, em 2020 e 2021, ampliamos o âmbito da formação docente dos tutores e temos atendido alunos de diversas partes do mundo.

O sucesso da formação complementar de professores de PLE nos CLDPs da UNESP não deve, todavia, impedir que haja planos e a concretização de uma formação em PLE mais robusta na referida universidade, por exemplo, com a criação daárea de PLE nos departamentos de Letras Modernas, a contratação de docentes-pesquisadores nessas áreas e a criação de licenciaturas específicas para a formação de docentes de português para falantes de outras línguas.

\section{REFERÊNCIAS}

ALMEIDA, J. C.; ROCHA, N. A. Formação inicial e continuada de professores de Português Língua Estrangeira/Segunda Língua no Brasil. SCRIPTA, v. 25, n. 53, p. 746-760, 2021. Disponível em: http://periodicos.pucminas.br/index.php/scripta/article/view/26122. Acesso em: 26 ago. 2021.

ALTET, M. Comment interagissent enseignant et élèves en classe? Revue Française de Pédagogie, n. 107, p. 16, 1991.

ALTET, M. La formation profissionnelle des enseignants. Paris: PUF, 1994.

CONSOLO, D. A. An online placement test of Portuguese as a foreign language:

Development and implementation. Portuguese Language Journal. (no prelo).

CONSOLO, D. A. Uma conversa sobre Avaliação no Ensino/Aprendizagem de Línguas com tutores dos CLDPs-UNESP. Palestra proferida aos tutores dos Centros de Línguas e Desenvolvimento de Professores das UNESP, 21 out. 2020. 
CONSOLO, D. A.; SILVA, V. P. Desenvolvimento e Implementação (Teste Online) de Proficiência de Português como Língua Estrangeira. MOSAICO, São José do Rio Preto, v. 15, p. 691-716, 2016.

CORDEIRO, K. M. A. O impacto da pandemia na educação: a utilização da tecnologia como ferramenta de ensino. 2020. Disponível em:

https://repositorio.idaam.edu.br/jspui/handle/prefix/1157. Acesso em: 01 ago. 2021.

FILHO, A. J. C. P. Ensino de português língua estrangeira/EPLE: a emergência de uma especialidade no Brasil. In: LOBO, T. et al. (org.). Rosae: linguística histórica, história das línguas e outras histórias. Salvador: Edufba, 2012.p. 723-728.

FURTOSO, V. A. B. Onde estamos? Para onde vamos? A Pesquisa em Português para Falantes de Outras Línguas nas Unjiversidades Brasileiras. In: LUCAS, P. O.; RODRIGUES, F. L. R. (org.) Temas e Rumos nas Pesquisas em Linguística (Aplicada): questões empíricas, éticas e práticas. Campinas, SP: Pontes Editores, 2015. p. 153-195.

HODGES, C. et al. The difference between emergency remote teaching and online learning. 2020. Disponível em: https://er.educause.edu/articles/2020/3/the-differencebetween-emergency-remote-teaching-and-online-learning\#disqus_thread. Acesso em: 30 jul. 2020 .

SAUJAT, F. O trabalho do professor nas pesquisas em educação: um panorama. In: MACHADO, A. R. (org.) O Ensino como Trabalho: uma abordagem discursiva. Londrina: EDUEL, 2004.p. 3-34.

SCARAMUCCI, M. V. R.; BIZON, A. C. C. (org.). Formação inicial e continuada de professores de Português Língua Estrangeira/Segunda Língua no Brasil. Araraquara: Letraria, 2020.

SCHÖN, D. A. The reflective practitioner. New York: Basic Book. 1983. 374 p.

\section{Como referenciar este artigo}

CONSOLO, D. A. Formação de professores de Português como Língua Estrangeira (PLE) em um centro de línguas em contexto universitário. Rev. EntreLínguas, Araraquara, v. 7, n. esp. 6, e021153, dez. 2021. e-ISSN: 2447-3529. DOI: https://doi.org/10.29051/el.v7iesp.6.15459

Submetido em: $31 / 08 / 2021$

Revisões requeridas em: 15/10/2021

Aprovado em: 29/11/2021

Publicado em: 28/12/2021 